

Revista Cientifica Mundo de la Investigación y el Conocimiento

Adriana Mercedes Andrade Toscano ${ }^{\text {a }}$; Cory Jorgelina Zuñiga Hurtado ${ }^{\text {b; }}$ María José Pacheco Coello ${ }^{c}$; D Anggeli Virginia Garzon Cuadro ${ }^{d}$

Lesión cardíaca producida por fiebre reumática

Heart injury caused by rheumatic fever

Revista Científica Mundo de la Investigación y el Conocimiento. Vol. 3 núm.3. Esp., noviembre, ISSN: 2588-073X, 2019, pp. 982-1001

DOI: $10.26820 /$ recimundo/3.(3.Esp).noviembre.2019.982-1001

URL: http://recimundo.com/index.php/es/article/view/640

Código UNESCO: 3205 Medicina Interna

Tipo de Investigación: Artículo de Revisión

(C) RECIMUNDO; Editorial Saberes del Conocimiento, 2019

Recibido: 15/09/2019

Aceptado: 23/10/2019

Publicado: 30/11/2019

Correspondencia: adry_andrade88@ hotmail.com

a. Médico; Investigadora Independiente; Guayaquil, Ecuador; adry_andrade88@ hotmail.com

b. Médico; Investigadora Independiente; Guayaquil, Ecuador; corita1987@ hotmail.com

c. Médico; Investigadora Independiente; Guayaquil, Ecuador; majosecita@ outlook.com

d. Médico; Investigadora Independiente; Guayaquil, Ecuador; dulce_dangc@ hotmail.com 


\section{Lesión cardíaca producida por fiebre reumática}

Vol. 3, núm. 3 Esp., (2019)

Adriana Mercedes Andrade Toscano; Cory Jorgelina Zuñiga Hurtado; María José Pacheco Coello; D Anggeli Virginia Garzon Cuadro

\section{RESUMEN}

En base a los ya establecidos DeCS (Descriptores en Ciencias de la Salud), la lesión cardíaca producida por fiebre reumática (FR) puede ser más propiamente definida como Cardiopatía Reumática (CR), no obstante, puede vincularse a otros términos tales como Artritis Reumática Aguda, Fiebre Reumática Aguda o Reumatismo Articular Agudo. La FR puede entenderse como la enfermedad febril que surge como consecuencia tardía de infecciones por streptococcus pyogenes y que puede afectar a cualquier parte del corazón, pero siendo más comunes las válvulas cardiacas y el endocardio. Igualmente es distinguida por varias lesiones inflamatorias focales de las estructuras de tejido conjuntivo, como corazón, vasos sanguíneos, articulaciones y encéfalo, a parte de la coexistencia de cuerpos de Aschoff en el miocardio y la piel. En el reciente siglo $\mathrm{XX}$, las complicaciones cardiovasculares se le estimó entre las patologías más graves. La presente investigación documental se enfoca en la revisión de la literatura científicoacadémica disponible de manera completa y libre en bases de datos tales como: BVS, ELSEVIER, PubMed, Intramed, SciELO, MedlinePlus, Dialnet, Cochrane y otras. El objetivo ha sido exponer fundamentalmente sobre lo que la literatura vigente refiere respecto a la cardiopatía reumática, así como también sobre lesiones cardíacas ocasionadas por la fiebre reumática. Los resultados obtenidos sirvieron para definir, además: cuáles son las complicaciones cardíacas que ello conlleva, es por lo que, a continuación, se define la fiebre reumática, la cardiopatía reumática, otros factores que pueden aumentar el riesgo de fiebre reumática, cómo se diagnóstica la fiebre reumática, cuáles podrían ser las lesiones o daños causados por la fiebre reumática y, finalmente, la carditis. En conclusión, el diagnóstico temprano y prevención de este tipo de complicaciones potencialmente fatales sigue siendo la norma, no solo para evitar su evolución a estados graves sino también para determinar el tratamiento más idóneo según las particularidades presentes en cada persona la cardiopatía reumática.

Palabras Claves: Artritis reumática aguda; Fiebre reumática aguda; Reumatismo articular agudo; Válvulas cardiacas; Endocardio. 


\section{Lesión cardíaca producida por fiebre reumática}

Vol. 3, núm. 3 Esp., (2019)

Adriana Mercedes Andrade Toscano; Cory Jorgelina Zuñiga Hurtado; María José Pacheco

Coello; D Anggeli Virginia Garzon Cuadro

\section{ABSTRACT}

Based on the already established DeCS (Descriptors in Health Sciences), the cardiac lesion caused by rheumatic fever (FR) can be more properly defined as Rheumatic Cardiopathy (CR), however, it can be linked to other terms such as Rheumatic Arthritis Acute, Acute Rheumatic Fever or Acute Articular Rheumatism. RF can be understood as the febrile illness that arises as a late consequence of streptococcus pyogenes infections and that can affect any part of the heart, but the heart valves and the endocardium being more common. It is also distinguished by several focal inflammatory lesions of connective tissue structures, such as heart, blood vessels, joints and brain, apart from the coexistence of Aschoff bodies in the myocardium and skin. In the recent twentieth century, cardiovascular complications were estimated among the most serious pathologies. This documentary research focuses on the review of the scientific and academic literature available in a complete and freeway in databases such as: VHL, ELSEVIER, PubMed, Intramed, SciELO, MedlinePlus, Dialnet, Cochrane and others. The objective has been to explain essentially what the current literature refers to rheumatic heart disease, as well as cardiac injuries caused by rheumatic fever. The results obtained also served to define: what are the cardiac complications that this entails, which is why, then, rheumatic fever, rheumatic heart disease, other factors that can increase the risk of rheumatic fever are defined, how the diagnosis is diagnosed rheumatic fever, what could be the injuries or damage caused by rheumatic fever and, finally, carditis. In conclusion, early diagnosis and prevention of this type of potentially fatal complications remains the norm, not only to avoid its evolution to serious conditions but also to determine the most suitable treatment according to the particularities present in each person rheumatic heart disease.

Keywords: Acute rheumatic arthritis; Acute rheumatic fever; Acute articular rheumatism; Cardiac valves; Endocardium. 


\section{Lesión cardíaca producida por fiebre reumática}

Vol. 3, núm. 3 Esp., (2019)

Adriana Mercedes Andrade Toscano; Cory Jorgelina Zuñiga Hurtado; María José Pacheco Coello; D Anggeli Virginia Garzon Cuadro

\section{Introducción.}

La fiebre reumática es un padecimiento inmunológico de todo el organismo provocado por el Estreptococo B hemolítico como consecuencia de una infección en la garganta. [...] La fiebre reumática La fiebre reumática es una enfermedad inflamatoria, no supurativa y recurrente producida por la respuesta del sistema inmunitario de algunos niños predispuestos, a los antígenos de la bacteria estreptococo del grupo A betahemolítico, a partir de las dos o tres semanas de provocar una faringoamigdalitis aguda. La fiebre reumática es una complicación tardía que puede afectar cualquier parte del organismo, siendo el principal órgano afectado es el corazón donde puede afectar el pericardio pericarditis, el miocardio miocarditis, o el endocardio endocarditis y en la fase aguda produce una pancarditis que provoca valvulopatías cardíacas en la fase crónica. La válvula mitral es atacada en un 75 a $80 \%$ de los casos, la aórtica es $30 \%$ y las válvulas tricúspide y pulmonar en menos de 5\%. (Fundación Belén, 2019).

La cardiopatía reumática se ubica como uno de los flagelos cardiovasculares más graves del siglo pasado. Como resultado de las mejoras en las condiciones de vida y la introducción de la penicilina, la enfermedad fue casi erradicada en el mundo desarrollado en la década de 1980. (Marijon, Celermajer, \& Jouven, 2017).

Papponetti afirma que, en la FR, los cuadros clínicos poco comunes están representados por los movimientos involuntarios anormales (corea), la erupción (eritema marginado) y los nódulos subcutáneos, mientras que la carditis (valvulitis) se da en cerca del $80 \%$ de las personas que padecen esta complicación, siendo de allí que por consiguiente sea frecuente las afecciones a las válvulas mitral y aórtica provocando regurgitación. Así mismo detalla que: 


\section{Lesión cardíaca producida por fiebre reumática}

Vol. 3, núm. 3 Esp., (2019)

Adriana Mercedes Andrade Toscano; Cory Jorgelina Zuñiga Hurtado; María José Pacheco

Coello; D Anggeli Virginia Garzon Cuadro

A nivel mundial, alrededor del $50-65 \%$ de las personas con FR tienen carditis clínicamente detectable (inflamación de las valvas cardíacas que conducen a insuficiencia valvular). La válvula mitral es la que más a menudo es afectada, seguida por la válvula aórtica. También se producen pericarditis y miocarditis. La carditis grave ocurre en aproximadamente el $20 \%$ y puede conducir a insuficiencia cardiaca congestiva. En casi el $30 \%$ de los casos, la carditis reumática puede ser subclínica, es decir, solo detectada por la ecocardiografía y no por la auscultación de soplos. La carditis reumática puede evolucionar a lo largo de semanas o meses, lo que destaca la importancia de la ecocardiografía repetida a las 2-4 semanas si el primer ecocardiograma es normal. (Papponetti, 2015).

La Organización Mundial de la Salud (OMS) en su 71. a Asamblea Mundial de la Salud ha dejado en evidencia que la situación actual de la cardiopatía reumática es, que aún "persiste en países de todas las regiones de la OMS", y que "es un problema de salud pública grave, pero prevenible, en los países de ingresos bajos y medios y en las comunidades marginadas de los países de ingresos altos, en particular en las poblaciones indígenas". Así mismo han informado indicado que la enfermedad

...se debe al daño de las válvulas cardiacas causado por uno o varios episodios de fiebre reumática, una reacción inflamatoria autoinmune a las infecciones faríngeas por estreptococos del grupo A (faringitis estreptocócica). Es más frecuente en la infancia y puede resultar mortal o causar discapacidad de por vida. Las intervenciones precoces eficaces pueden prevenir la mortalidad prematura por cardiopatía reumática. [...] Se cree que en el mundo hay unos 30 millones de personas con cardiopatía reumática, y se calcula que en 2015 ocasionó 305.000 muertes y la pérdida de 11,5 


\section{Lesión cardíaca producida por fiebre reumática}

Vol. 3, núm. 3 Esp., (2019)

Adriana Mercedes Andrade Toscano; Cory Jorgelina Zuñiga Hurtado; María José Pacheco Coello; D Anggeli Virginia Garzon Cuadro

millones de años de vida ajustados en función de la discapacidad. El 60\% de esas muertes fueron prematuras (antes de los 70 años), aunque estas cifras son muy inciertas porque los datos son incompletos en muchos países. Pese a la disponibilidad de medidas preventivas y terapéuticas eficaces, la contribución de la cardiopatía reumática a la mortalidad general mundial ha cambiado poco entre 2000 y 2015. [...] Los factores socioeconómicos y ambientales, como la precariedad de la vivienda, la desnutrición, el hacinamiento y la pobreza son factores bien conocidos que contribuyen a la incidencia, magnitud y gravedad de la fiebre reumática y la cardiopatía reumática. (OMS, 2018).

De coformidad con el Perfil De Enfermedades Cardiovasculares - Ecuador ofrecido por la OMS (2014), para 2025 se estima que la tendencia por muerte prematura por enfermedades cardiovasculares disminuya significativamente en comparación con los valores historicos desde el año 2000, sin embargo, mediante otro tipo de reporte la OMS (2018) ha evidenciado un incremento en la morbilidad y mortalidad por las enfermedades crónicas no transmisibles, así como también se deja ver que las enfermedades infecciosas aún son persistentes; entre las que figura la cardiovascular.

En este trabajo, el enfoque se mntendrá en referir lo concerniente a la cardiopatía reumática, detallando cuáles son las complicaciones cardíacas que ello conlleva, es por lo que, a continuación, se define la fiebre reumática, la cardiopatía reumática, otros factores que pueden aumentar el riesgo de fiebre reumática, cómo se diagnóstica la fiebre reumática, cuáles podrían ser las lesiones o daños causados por la fiebre reumática y, finalmente, la carditis. 


\section{Lesión cardíaca producida por fiebre reumática}

Vol. 3, núm. 3 Esp., (2019)

Adriana Mercedes Andrade Toscano; Cory Jorgelina Zuñiga Hurtado; María José Pacheco

Coello; D Anggeli Virginia Garzon Cuadro

\section{Materiales y Métodos.}

El presente trabajo se basa en un diseño documental y se enmarca dentro de una metodología de revisión con el objeto de encontrar discutir e interpretar la literatura cientificoacadémica escogida y accedida de manera completa y libre de las bases de datos: PubMed, BVS, Intramed, SciELO, MedlinePlus, Dialnet, Cochrane y otras.

La búsqueda se inició de manera aleatoria considerando particularmente las expresiones "fiebre reumática", "cardiopatía reumática" y "trastornos por cardiopatía reumática". Los resultados en conjunto sumaron más de 500 registros bibliográficos de diversa índole, que evidentemente se tuvo que ir reduciendo para en definitiva referir sólo aquellas que respondiera a los propios criterios de selección, que básicamente se referían a: pertinencia y correlatividad temática, idioma español e inglés, publicación en los últimos diez años, incluido el presente, sin descartar por tipo de material bibliográfico; es decir, se escogen primordialmente artículos científicos originales, revisiones sistemáticas con y sin metaanálisis, protocolos, libros electrónicos, libros digitalizados, boletines, folletos, tesis de grado, posgrado y doctorado, noticias científicas, entre otros documentos e información de interés científico y académico.

Luego, en base a un cúmulo de aproximadamente 20 contenidos bibliográficos diversos, se efectúa el análisis, interpretación y discusión de dicho material, tratado como evidencia científico-académica, proceso con el que, consensuadamente, se logra determinar y expresar los argumentos aquí expuestos.

Finalmente, todas las opiniones encontradas, así como también las inclusiones y exclusiones de cada cita y/o referencia de este trabajo investigativo, fueron igualmente resueltas 


\section{Lesión cardíaca producida por fiebre reumática}

Vol. 3, núm. 3 Esp., (2019)

Adriana Mercedes Andrade Toscano; Cory Jorgelina Zuñiga Hurtado; María José Pacheco Coello; D Anggeli Virginia Garzon Cuadro

de manera grupal, sin que se llegase a mantener algún disenso de intereses entre los autores.

\section{Resultados.}

En el Instituto del corazón de Texas de Estados Unidos de América, la fiebre reumática es concebida como la complicación de una amigdalitis estreptocócica no tratada, en donde ésta última a su vez es causada por una infección por estreptococos del grupo A presente en la garganta. Adicionalmente afirman que ésta patología "puede dañar los tejidos del organismo causando hinchazón, aunque el mayor peligro de la enfermedad es el daño que puede ocasionar al corazón". Esta complicación "produce una cicatrización de las válvulas del corazón, particularidad que puede estrechar la válvula y hacer que sea más difícil que ésta se abra bien o se cierre por completo" en más del 50\% de las veces. Otro efecto paralelo es que "el corazón tiene que esforzarse más por bombear sangre al resto del organismo". Es entonces como el referido daño valvular puede generar lo que se define como «cardiopatía reumática» condición que a posteriori "puede ocasionar una insuficiencia cardíaca congestiva". (Texas Heart Institute, s.f.).

Freire, Valdez, Montenegro, \& Rivera (2018) hacen referencia a la exposición que en 2017 Mayo Clinic ha aportado sobre esta enfermedad inflamatoria, puesto que alegan es común en niños de entre 5 y 15 años de edad, y además:

...es contraída por no haber tratado adecuadamente una faringitis estreptocócica o fiebre escarlatina complicadas, causadas por una infección con la bacteria estreptocócica; sin embargo, eso no significa que un adulto o niño de menos edad que los antes referido, puedan igualmente contraerla. Además, puede causar daños cardíacos 


\section{Lesión cardíaca producida por fiebre reumática}

Vol. 3, núm. 3 Esp., (2019)

Adriana Mercedes Andrade Toscano; Cory Jorgelina Zuñiga Hurtado; María José Pacheco

Coello; D Anggeli Virginia Garzon Cuadro

permanentes, "incluidos el daño en las válvulas cardíacas y la insuficiencia cardíaca", no obstante, su tratamiento facilita potencialmente la reducción de dichos daños causados por la inflamación, alivian el dolor y los otros síntomas, aparte de que previene la reaparición esta patología.

Así mismo, citan a (Gutiérrez, 2015) quien coincide expresando que:

La cardiopatía reumática está causada por la lesión de las válvulas cardiacas y el miocardio derivada de la inflamación y la deformación cicatrizal ocasionada por la fiebre reumática. Es generada por una respuesta anormal del organismo ante una infección con bacterias estreptocócicas, que suele manifestarse en forma de dolor de garganta o amigdalitis en los niños.

Seguidamente estos tratadistas complementan con la idea de (Schroh, 2019) quien deja claro que, a nivel mundial, esta condición representa una causa importante de enfermedad cardiaca "y ocurre luego de uno o más episodios de fiebre reumática, una condición asociada con una respuesta inmune inapropiada a la infección por el Estreptococo del Grupo A.”

A pesar de estos criterios actuales, se debe tener claro que, desde hace más de veinte años, autores como Velázquez indicaban que:

Debido a que la recurrencia de la fiebre reumática es mayor durante los 3 a 5 años subsiguientes a un primer episodio en niños y que el riesgo de reinfección continúa tanto en adultos como en ancianos; es que se recomienda el tratamiento profiláctico de 


\section{Lesión cardíaca producida por fiebre reumática}

Vol. 3, núm. 3 Esp., (2019)

Adriana Mercedes Andrade Toscano; Cory Jorgelina Zuñiga Hurtado; María José Pacheco Coello; D Anggeli Virginia Garzon Cuadro

por vida. Conviene resaltar que, en pacientes adultos, la fiebre reumática se manifiesta de forma diferente que en niños y adolescentes. Por este motivo cuando aparece un episodio de actividad reumática en el adulto (que usualmente ya padece valvulopatía resultante de episodios anteriores), sin manifestaciones sistémicas, es muy difícil reconocer si la cardiomegalia, insuficiencia cardíaca o arritmia se deben a la valvulopatía ya establecida o es consecuencia de un nuevo brote de la enfermedad. Es por ello que los nuevos episodios de actividad reumática pueden pasar inadvertidos, conduciendo a daño valvular y miocárdico progresivo. (Velázquez, 2004).

En resumen, la cardiopatía reumática fisiopatológicamente se refiere a cambios crónicos de las válvulas del corazón que ocurren luego de repetidos de fiebre reumática aguda.

La cardiopatía reumática afecta predominantemente las válvulas del lado izquierdo del corazón (válvula mitral y válvula aórtica) y la válvula mitral tiende a verse más frecuentemente afectada que la válvula aórtica. Es muy raro que solo la válvula aórtica se vea afectada. La cardiopatía reumática resulta en cicatrices, espesamiento o rigidez de las válvulas cardíacas y como resultado no funcionan como corresponde. El daño de las válvulas mitral puede hacer que las mismas: 1) no cierren como corresponde durante la sístole, cuando el ventrículo izquierdo se contrae, siendo esto lo que hace que la sangre regrese a la aurícula izquierda través de la válvula mitral, es decir, lo que se conoce como Regurgitación Mitral (RM) o insuficiencia; y 2) no abran por completo durante la diástole, ocasionando una reducción del flujo de la sangre hacia el ventrículo izquierdo a través de la válvula mitral, resultando en el estrechamiento de la válvula, y todo este proceso se le conoce como Estenosis Mitral (EM). En la válvula aórtica puede darse: 1) regurgitación aortica (RA): referida a la fuga que ocurre a través de la válvula aortica, misma que 


\section{Lesión cardíaca producida por fiebre reumática}

Vol. 3, núm. 3 Esp., (2019)

Adriana Mercedes Andrade Toscano; Cory Jorgelina Zuñiga Hurtado; María José Pacheco

Coello; D Anggeli Virginia Garzon Cuadro

no cierra como corresponde durante la diástole, posterior al bombeo de sangre del ventrículo izquierdo hasta la aorta; y 2) Estenosis aórtica (EA): que se origina tempranamente en el transcurso de la enfermedad, por el escaso flujo de sangre a través de la válvula hacia la aorta, en razón de la apertura incompleta de la válvula aórtica durante la sístole. La estenosis por lo general ocurre más adelante en la cardiopatía reumática y a menudo coexiste con la regurgitación que se da más tempranamente. (Wired International, s.f.).

Algunos factores que pueden aumentar el riesgo de fiebre reumática son:

- Los antecedentes familiares; debido a que algunas personas tienen un gen o genes que hacen que tengan más posibilidades de contraer fiebre reumática.

- El tipo de bacteria estreptocócica; ya que determinadas cepas de estreptococos tienen mayores probabilidades de causar fiebre reumática que otras.

- Factores del entorno; en razón de la relación existente entre la superpoblación, malas condiciones de higiene y otras afecciones y un mayor riesgo de padecimiento de esta enfermedad. (Mayo Clinic, 2017).

\section{Diagnóstico}

No hay ninguna prueba de laboratorio ni signo clínico que sea patognomónico de FR. El diagnóstico se basa en el conjunto de hallazgos clínicos y en los datos biológicos. Los criterios de Jones sirven para el diagnóstico del brote agudo inicial. La FR se define como un síndrome inflamatorio evolutivo con una infección estreptocócica previa. Los criterios de Jones, revisados 


\section{Lesión cardíaca producida por fiebre reumática}

Vol. 3, núm. 3 Esp., (2019)

Adriana Mercedes Andrade Toscano; Cory Jorgelina Zuñiga Hurtado; María José Pacheco Coello; D Anggeli Virginia Garzon Cuadro

varias veces, sirven como guía. La asociación de 2 criterios mayores o uno mayor y 2 menores, junto con la existencia de signos evidentes de infección estreptocócica reciente, hacen muy probable el diagnóstico de FR. Actualmente en los países más desarrollados la FR está en retroceso y los casos esporádicos que se presentan tienen una evo-lución distinta al cuadro clásico, por lo que el diagnóstico es más complicado y los errores son frecuentes. Se aplican mal los criterios de Jones y se confunden artralgias con artritis, soplos funcionales con orgánicos, se interpreta como carditis el hallazgo de taquicardia o P-R alargado y el error más frecuente es considerar que son una FR los cuadros inespecíficos de poliartralgias con ASLO elevadas. (RosViladoms, 2010, pág. 21).

Por su parte, el Centro de Salúd Infantil de Stanford (2019) indica que para el diagnóstico de la enfermedad cardíaca reumática, inicialmente el médico tratante debe informarse sobre los síntomas del paciente y su historia clínica, incluida la ocurrencia de infecciones por estreptococos o fiebre reumática, así como también debe efectuar un examen físico y, posiblemente otros análisis y pruebas, tales como:

- Electrocardiografía; que se trata de una prueba para medir la actividad eléctrica del corazón.

- Ecocardiografía: referida a una prueba que, mediante el uso de ondas sonoras (ultrasonido), produce imágenes detalladas del corazón.

- Análisis de sangre. (Centro de Salúd Infantil de Stanford, 2019).

\section{Lesiones o daños causados por la fiebre reumática}

Antón (2013) aporta que: 


\section{Lesión cardíaca producida por fiebre reumática}

Vol. 3, núm. 3 Esp., (2019)

Adriana Mercedes Andrade Toscano; Cory Jorgelina Zuñiga Hurtado; María José Pacheco

Coello; D Anggeli Virginia Garzon Cuadro

Los individuos susceptibles al agente causal de la fiebre reumática presentan una respuesta autoinmune exagerada frente a este agente infeccioso y desarrollan una enfermedad inflamatoria que puede afectar al corazón, articulaciones, cerebro, vasos sanguíneos y tejido subcutáneo. Aunque el proceso agudo causa una considerable morbilidad y cierta mortalidad, la mayor implicación clínica deriva de la lesión a largo plazo por la enfermedad cardiaca reumática (ECR) y, en concreto, por la afectación de las válvulas cardiacas. Las principales manifestaciones clínicas se incluyen entre los Criterios de Jones. Los mayores son: artritis, carditis, corea de Sydenham, eritema marginado y nódulos subcutáneos; y los menores son: artralgias, fiebre, aumento de los reactantes de fase aguda e intervalo PR alargado. No obstante, hay que tener en cuenta que estos criterios son sólo una guía diagnóstica. (p. 48, 50).

En síntesis, pudiera precisarse que la fiebre reumática, cuando efectivamente lesiona a nivel cardíaco, básicamente lo hace sobre las válvulas cardiacas y el miocardio, producto de la inflamación y la deformación cicatrizal.

Es por ello que, entonces, al referirse a las lesiones cardíacas producidas por la fiebre reumática, es propio aludir a la carditis que esta condición generalmente suele provocar tras no haber tratado oportunamente la fiebre reumática.

La carditis ocurre entre un 40 y 60 por ciento de las veces y puede representar afecciones en el endocardio, miocardio y pericardio; con mayor frecuencia cursa con soplo de insuficiencia mitral. En el ECG a menudo se observa un bloqueo AV de I grado, y con menor frecuencia bloqueos más avanzados. (Medicina Interna Basada en la Evidencia, 2019). 


\section{Lesión cardíaca producida por fiebre reumática}

Vol. 3, núm. 3 Esp., (2019)

Adriana Mercedes Andrade Toscano; Cory Jorgelina Zuñiga Hurtado; María José Pacheco Coello; D Anggeli Virginia Garzon Cuadro

\section{Carditis}

Es la afectación más grave, y puede suponer la muerte en la fase aguda o provocar graves secuelas valvulares. Se trata de una pancarditis que afecta a todas las estructuras cardíacas, pero principalmente a las valvas. Puede tener cuatro manifestaciones clínicas diferentes: aparición de un soplo cardíaco significativo que antes no existía, presencia de cardiomegalia, insuficiencia cardíaca congestiva y presentación de una pericarditis. Los soplos significativos que se pueden presentar son:

1. Soplo cardíaco apical de insuficiencia mitral. El más frecuente, es un soplo holosistólico, intenso II-III/VI, que suele irradiar a la axila.

2. Soplo mesodiastólico corto y suave en punta llamado de Carey-Coombs, debido a una turbulencia diastólica por regurgitación sanguínea en aurícula izquierda.

3. Soplo protodiastólico en foco aórtico debido a insuficiencia aórtica.

La cardiomegalia ocurre por dilatación de las cavidades, principalmente las izquierdas, y traduce la participación miocárdica en el proceso. Se presenta en el $80 \%$ de los casos. Se puede detectar por radiología de tórax, electrocardiograma (ECG) y esofagograma.

El fallo cardíaco congestivo o insuficiencia cardíaca se produce con menos frecuencia, en el 5-10\% de casos, y cursa con dificultad respiratoria, taquicardia, ritmo de galope y hepatomegalia, entre otros.

La pericarditis no suele presentarse aisladamente sino en el contexto de la pancarditis. Clínicamente cursa con dolor precordial, dificultad respiratoria y roce pericárdico. Se puede 


\section{Lesión cardíaca producida por fiebre reumática}

Vol. 3, núm. 3 Esp., (2019)

Adriana Mercedes Andrade Toscano; Cory Jorgelina Zuñiga Hurtado; María José Pacheco

Coello; D Anggeli Virginia Garzon Cuadro

diagnosticar por radiología y por las alteraciones del ECG, que muestran voltajes bajos y afectación del segmento ST y de la onda T, además del estudio por ecocardiografía.

También podemos encontrar signos menores de carditis: taquicardia en reposo, ritmo de galope, primer ruido apagado, etc. En el ECG lo más significativo es la prolongación del intervalo ST, que indica lesión cerca del nodo A-V. Se aprecia entre el 40 y el $61 \%$ de casos. Otro hallazgo son las arritmias, los bloqueos $\mathrm{A}-\mathrm{V}$ de segundo grado, los trastornos de repolarización con aumento del ST y aplanamiento de la onda T. (Ros-Viladoms, 2010).

Estenosis de la válvula mitral

Referido a un "estrechamiento de la apertura de la válvula mitral, aumentando la resistencia del flujo de la sangre desde el atrio izquierdo hasta el ventrículo izquierdo.” (GW Heart \& Vascular Institute, 2019).

\section{Estenosis de la válvula aortica}

También conocida como estenosis aórtica,

se produce cuando la válvula aórtica del corazón se estrecha. Este estrechamiento impide que la válvula se abra por completo, lo que reduce u obstruye el flujo sanguíneo del corazón a la arteria principal del cuerpo (aorta) y hacia el resto del organismo. Cuando el flujo de sangre que pasa por la válvula aórtica se reduce o se obstruye, el corazón debe trabajar más para bombear sangre al cuerpo. Con el tiempo, este esfuerzo adicional limita la cantidad de sangre que puede bombear el corazón, lo que puede provocar síntomas y, posiblemente, debilitar el músculo cardíaco. (Mayo Clinic, 2018). 


\section{Lesión cardíaca producida por fiebre reumática}

Vol. 3, núm. 3 Esp., (2019)

Adriana Mercedes Andrade Toscano; Cory Jorgelina Zuñiga Hurtado; María José Pacheco Coello; D Anggeli Virginia Garzon Cuadro

\section{Insuficiencia mitral}

Es la incompetencia de la válvula mitral que moviliza el flujo desde el ventrículo izquierdo hacia la aurícula izquierda durante la sístole ventricular. La insuficiencia mitral puede ser primaria (son causas frecuentes el prolapso de la válvula mitral y la fiebre reumática) o secundaria a dilatación del ventrículo izquierdo o infarto. (Armstrong, 2016).

\section{Insuficiencia aortica}

Se produce por el cierre defectuoso de la válvula aórtica que genera una fuga (regurgitación) de sangre desde la aorta hacia el ventrículo izquierdo en cada latido. Esta fuga de sangre, genera una sobre carga de volumen en el ventrículo izquierdo que con el tiempo puede dilatarse. (Clínica Universitaria de Navarra, 2019).

\section{Conclusiones.}

Mientras se controlen las faringitis por EBHGA, se estará cumpliendo el primer paso preventivo para no desarrollar Fiebre Reumática. Aunque la mayoría de los cuadros de faringoamigdalitis son de etiología viral, es recomendable que todos los casos de amigdalitis o faringitis exudativa deben ser tratados apropiadamente con antibióticos, aún sin haber confirmado la presencia del EBHGA. Este organismo continúa siendo susceptible a la penicilina in vitro por lo que no hay razón justificada para que la penicilina benzatínica no sea la primera elección en el tratamiento de esta enfermedad, siempre y cuando no sea alérgico a la misma, es recomendable el uso de la penicilina benzatínica y no la forma oral u otras formas parenterales disponibles. Como es difícil que el paciente cumpla tratamiento oral continuo por varioa años se 


\section{Lesión cardíaca producida por fiebre reumática}

Vol. 3, núm. 3 Esp., (2019)

Adriana Mercedes Andrade Toscano; Cory Jorgelina Zuñiga Hurtado; María José Pacheco

Coello; D Anggeli Virginia Garzon Cuadro

prefiere asegurar el tratamiento con la penicilina benzatínica intramuscular cada 3 semanas como profilaxis pues una recaída puede traer consecuencias cardíacas severas. El esquema de aplicación de la penicilina benzatínica cada 4 semanas es inefectivo y no debe utilizarse. (Mas Romero, Gutiérrez Álvarez, \& Yong Piñar, 2005)

Partiendo nuevamente del hecho de que esta complicación es plenamente previsible, resulta trascendental el diagnóstico oportuno.

En la reciente $71^{\mathrm{a}}$ Asamblea Mundial de la Salud sobre la fiebre reumática y cardiopatía reumáticase dejó constancia de "[...] que la cardiopatía reumática es una causa importante y prevenible de morbilidad y mortalidad en todas las regiones de la OMS", es reconocido que ser su temprano diagnóstico favorezca la reducción de "la morbilidad y la mortalidad de forma costoeficaz" manera considerable. (Asamblea Mundial de la Salud, 71, 2018).

Retomando lo expresado por la dirección de la Organización Panamericana de la Salud (OPS) refiriéndose a las enfermedades no transmisibles (entre las que se encuentra la fiebre reumática) dijo "son la plaga de nuestro tiempo", enfatizando que "se debe mantener un mensaje simple, efectivo e invertir más en su comunicación” de dichas enfermedades. En definitiva, culmina alegando que "si queremos ser exitosos en revertir la catástrofe que están causando las ENT necesitamos un movimiento social masivo, nada menos" (OPS, 2019).

\section{Bibliografía.}

Antón, J. (2013). Fiebre reumática y artritis reactivas post-estreptocócica . Pediatría Integral, 7(1), 47-56. 


\section{Lesión cardíaca producida por fiebre reumática}

Vol. 3, núm. 3 Esp., (2019)

Adriana Mercedes Andrade Toscano; Cory Jorgelina Zuñiga Hurtado; María José Pacheco Coello; D Anggeli Virginia Garzon Cuadro

Armstrong, G. (Septembre de 2016). Insuficiencia mitral. Obtenido de MSD Manuals: https://www.msdmanuals.com/es-ve/professional/trastornoscardiovasculares/enfermedades-valvulares/insuficienciamitral?query=Insuficiencia\%20mitral\%20secundaria

Asamblea Mundial de la Salud, 71. (2018). 71. ${ }^{\text {a }}$ Asamblea Mundial de la Salud. Fiebre reumática y cardiopatía reumática (págs. 1-3). Ginebra: WHO. Recuperado el 26 de 07 de 2019, de https://apps.who.int/iris/handle/10665/279548

Centro de Salúd Infantil de Stanford. (2019). Enfermedad cardíaca reumática en los niños. (Stanford Children's Health) Obtenido de Stanford Childrens: https://www.stanfordchildrens.org/es/topic/default?id=cardiopatareumtica-90-P04919

Clínica Universitaria de Navarra. (2019). Insuficiencia aórtica. Obtenido de Clínica Universitaria de Navarra: https://www.cun.es/enfermedadestratamientos/enfermedades/insuficiencia-aortica

Freire, S., Valdez, S., Montenegro, A., \& Rivera, L. (2018). Cardiopatía reumática diagnóstico y tratamiento. Reciamuc|, 3(2), 1071-1085.

Fundación Belén. (2019). Fiebre Reumática. Obtenido de Fundación Belén: https://fundacionbelen.org/base-datos/fiebre-reumatica/

GW Heart \& Vascular Institute. (2019). Enfermedades Valvulares del Corazón. Obtenido de GW Heart \& Vascular Institute: http://www.gwheartandvascular.org/education/enespanol/enfermedades/enfermedades_condiciones/enfermedades_condiciones_valvulares/

Marijon, E., Celermajer, D., \& Jouven, X. (2017). Rheumatic Heart Disease-An Iceberg in Tropical Waters. New England Journal Medicine, 377(8), 780-781.

Mas Romero, C. F., Gutiérrez Álvarez, R., \& Yong Piñar, B. (2005). Mas Romero, C., Faerron Ángel, J., Castro Bermúdez, A., Gutiérrez Âlvarez, R., \& Yong Piñar, B. (2005). Fiebre reumática, Consenso Nacional 2005. Revista Costarricense de Cardiología, 7(1), 59-62.

Mayo Clinic. (17 de Noviembre de 2017). Fiebre reumática. Obtenido de Mayo Clinic: https://www.mayoclinic.org/es-es/diseases-conditions/rheumatic-fever/symptomscauses/syc-20354588

Mayo Clinic. (21 de Septiembre de 2018). Estenosis de la válvula aórtica. Obtenido de Mayo Clinic: https://www.mayoclinic.org/es-es/diseases-conditions/aortic-stenosis/symptomscauses/syc-20353139

Medicina Interna Basada en la Evidencia. (2019). Fiebre reumática. Obtenido de Empendium: https://empendium.com/manualmibe/chapter/B34.II.2.14. 


\section{Lesión cardíaca producida por fiebre reumática}

Vol. 3, núm. 3 Esp., (2019)

Adriana Mercedes Andrade Toscano; Cory Jorgelina Zuñiga Hurtado; María José Pacheco

Coello; D Anggeli Virginia Garzon Cuadro

OMS. (2014). Perfil de enfermedades cardiovascualares. Obtenido de PAHO: https://www.paho.org/hq/dmdocuments/2014/ECUADOR-PERFIL-ECV-2014.pdf

OMS. (Mayo de 2018). Estrategias de Cooperación. Resumen Ecuador. Obtenido de OMS: https://apps.who.int/iris/bitstream/handle/10665/137163/ccsbrief_ecu_en.pdf?sequence=1

OMS. (12 de Abril de 2018). Fiebre reumática y cardiopatía reumática. Obtenido de World Health Organization: https://apps.who.int/iris/bitstream/handle/10665/276480/A71_25sp.pdf

OPS. (2019). Comunicar efectivamente sobre las enfermedades no transmisibles es un gran desafío. Organización Panamericana de Salud. Washington, D.C. : Oficina Regional para las Américas de la Organización Mundial de la Salud. Recuperado el 26 de 07 de 2019, de

https://www.paho.org/hq/index.php?option=com_content\&view=article\&id=15171:comu nicar-efectivamente-sobre-las-enfermedades-no-transmisibles-es-un-grandesafio\&Itemid $=72512 \&$ lang $=\mathrm{es}$

Papponetti, M. (03 de Agosto de 2015). Fiebre reumática aguda. Obtenido de Intramed: https://www.intramed.net/contenidover.asp?contenidoid=87364

Ros-Viladoms, J. (2010). Fiebre reumática: una enfermedad emergente. Anales de Pediatría, $8(1), 17-25$.

Texas Heart Institute. (s.f.). Fiebre reumática. Obtenido de Texas Heart Institute: https://www.texasheart.org/heart-health/heart-information-center/topics/fiebre-reumatica/

Velázquez, B. (2004). Producciòn de estreptolisina-O recombinante para uso diagnóstico. Montevideo: Facultad de Ciencias - Universidad de la República. Recuperado el 26 de 11 de 2019, de http://www.bioero.com/salud/fiebre-reumatica-lo-que-usted-debe-saber.html

Wired International. (s.f.). Fisiopatología de la Cardiopatía Reumática. Obtenido de Wired International:

http://www.wiredhealthresources.net/EchoProject/modules/spanish/03/story_html5.html 


\section{Lesión cardíaca producida por fiebre reumática}

Vol. 3, núm. 3 Esp., (2019)

Adriana Mercedes Andrade Toscano; Cory Jorgelina Zuñiga Hurtado; María José Pacheco Coello; D Anggeli Virginia Garzon Cuadro

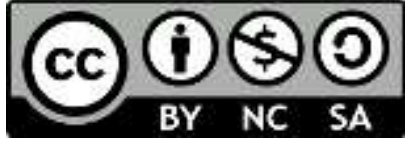

RECONOCIMIENTO-NOCOMERCIAL-COMPARTIRIGUAL

CC BY-NC-SA

ESTA LICENCIA PERMITE A OTROS ENTREMEZCLAR, AJUSTAR Y CONSTRUIR A PARTIR DE SU OBRA CON FINES NO COMERCIALES, SIEMPRE Y CUANDO LE RECONOZCAN LA AUTORÍA Y SUS NUEVAS CREACIONES ESTÉN BAJO UNA LICENCIA CON LOS MISMOS TÉRMINOS. 